Editorial

\title{
Pollutant Formation and Control during Fuel Thermochemical Conversion
}

\author{
Yanqing Niu $\mathbb{D}^{1},{ }^{1}$ Kuihua Han, ${ }^{2}$ Ningbo Gao $\mathbb{D}^{\circ},{ }^{1}$ Liang Wang, ${ }^{3}$ and Norbert Miskolczi ${ }^{4}$ \\ ${ }^{1}$ State Key Laboratory of Multiphase Flow in Power Engineering, School of Energy and Power Engineering, \\ Xi'an Jiaotong University, 710049 Xi'an, Shaanxi, China \\ ${ }^{2}$ Shandong Engineering Laboratory for High-efficiency Energy Conservation and Energy Storage Technology \& Equipment, \\ School of Energy and Power Engineering, Shandong University, 250061 Jinan, Shandong, China \\ ${ }^{3}$ SINTEF Energy Research, Sem Saelands vei 11, 7034 Trondheim, Norway \\ ${ }^{4}$ University of Pannonia, Faculty of Engineering, Institute of Chemical Engineering and Process Engineering, \\ MOL Department of Hydrocarbon \& Coal Processing, Egyetem u. 10, H-8200 Veszprém, Hungary \\ Correspondence should be addressed to Yanqing Niu; yqniu85@mail.xjtu.edu.cn
}

Received 3 August 2020; Accepted 4 August 2020; Published 26 November 2020

Copyright (C) 2020 Yanqing Niu et al. This is an open access article distributed under the Creative Commons Attribution License, which permits unrestricted use, distribution, and reproduction in any medium, provided the original work is properly cited.

The pollution emissions from the utilization of fuels have become a troublesome global problem due to its severe hazard to both human health and the environment. The pollutants emissions, such as $\mathrm{SO}_{2}$, nitric oxides $\left(\mathrm{NO}_{x}\right), \mathrm{CO}_{2}$, heavy metals, and particulate matters (PM), have limited the utilization of environmental-friendly fuels and require to be reduced [1-4]. These pollutants come from the combustion, gasification, and pyrolysis process of coal, biomass, wastederived fuels, and other solid fuels $[1,5]$. Regulations and legislations are being updated for limiting emissions from thermal conversion of fuels and negative effects to human health and environment. There are ongoing research activities and technology development aiming at understanding, controlling, and preventing formation and emission of these pollutants. Thus, the aim of this special issue was to publish research papers addressing recent advances on the fuel thermochemistry and the following pollution issues.

After the evaluation of manuscripts submitted to the special issue, we have accepted ten for publication in the special issue. Liu and coworkers investigated the influence of inner and secondary air ratios (ISA/OSA) on the coal combustion characteristic and flame shape. In particular, the study was carried out in a swirl burner with a prechamber in a $14 \mathrm{MW}$ pilot scale pulverized-coal combustion system. They found that the flame shape size exhibited an inflection point with increasing ISA/OSA and the ratio of $1: 2$ was the optimized case under experiment conditions.

$\mathrm{Xu}$ and coworkers studied the denitrification of decomposing furnace for $\mathrm{NO}_{x}$ reduction. They modeled the $2500 \mathrm{t} / \mathrm{d}$ new dry-process cement kiln decomposing furnace and verified the simulation methods by the field test. They concluded that the $\mathrm{NO}$ concentration, $\mathrm{NH}_{3}$ escape, and denitrification efficiency could be limited to $187.60 \mathrm{mg} / \mathrm{m}^{3}$, $32.40 \mathrm{mg} / \mathrm{m}^{3}$, and $74.75 \%$, respectively.

Huang and coworkers built a reactor network analysis model with a detailed mechanism to describe and calculate the process in the sulfur recovery unit. Then, they used the verified model to find the optimum condition parameters for a real device in the Puguang gas field. The results were able to correlate to the best sulfur recovery to reduce pollution emissions and improve economic performance.

$\mathrm{Yu}$ and coworkers simulated the $\mathrm{CO}_{2}$ emissions of China's power industry with different carbon tax levels based on the TIMES model. They quantitatively studied the power consumption demand, primary energy consumption structure, $\mathrm{CO}_{2}$ emission characteristics, emission reduction potential, and cost of different carbon tax levels. The authors predicted the peak value of $\mathrm{CO}_{2}$ emissions during 2030-2040; the medium carbon tax level was recommended for the most elastic impact on the national economy and the smallest GDP loss. 
Wang and coworkers concerned the mechanism of chlorine corrosion to heating surface in the boiler for corrosion prevention and the safety of boiler operation. They studied the reaction kinetics of chlorine corrosion by the weight gain method and simulated the temperature, atmosphere, and fouling in the boiler. The authors reported a fast corrosion rate in the early stage of ash deposits but a slower rate after the formation of the protective layer on heat transfer tube surfaces. Low temperature and concentration of $\mathrm{HCl}$ in the gas phase were suggested. Another work by the authors is the investigation on the corrosion mechanism related to ash deposition on the boiler heating surface. They concluded that the addition of biomass aggravated the corrosion of metal tubes, and T91 was the ideal material for the biomass-fired boiler against metal corrosion.

Lin and coworkers investigated the effect of $\mathrm{B}_{2} \mathrm{O}_{3}$ additives on the crystal behavior of high Ti-bearing blast furnace slag. The authors concluded that the $\mathrm{B}_{2} \mathrm{O}_{3}$ additives can restrain the appearance of the perovskite phase, decrease the apparent viscosity, and promote the metallurgical properties of Ti-bearing blast furnace slag. Their findings provided a feasible and convenient method to prevent the slagging problem for Ti-bearing blast furnaces.

Mohamed and coworkers aim to synthesize $\mathrm{Cr}$ (III), $\mathrm{Mn}$ (II), Fe (III), Co (II), Ni (II), Cu (II), Zn (II), and Cd (II) complexes with the new diazo ligand $\left(\mathrm{H}_{2} \mathrm{~L}\right)$ and to examine their physical properties involving spectral behaviors and the electrical conductance values. They determined the efficiency of the synthesized complexes against pathogenic bacteria and obtained the contact angle, molecular structure, and molecular docking. The results showed that the Cd (II) complex can be considered as a super hydrophobic material and has significant biological activities with different sensitivity levels. The binding between H2L and its Cd (II) complex with receptors of crystal structure of S. aureus (PDB ID: 3Q8U), crystal structure of protein phosphatase (PPZ1) of Candida albicans (PDB ID: 5JPE), receptors of breast cancer mutant oxidoreductase (PDB ID: 3HB5), and crystal structure of Escherichia coli (PDB ID: 3T88) was predicted and given in details.

Finally, this special issue includes two comprehensive reviews. Wang and coworkers reviewed the urea pyrolysis in three parts: urea pyrolysis pathway, catalytic hydrolysis of HNCO, and catalytic pyrolysis of aqueous urea solution. They proposed that the current research focused on the analysis of urea pyrolysis products and exploration of catalysts used to improve ammonia yields, but the mechanism study and development of a kinetic model with high accuracy need further exploration. Hameed and coworkers presented the state-of-the-art review on utilizing biomass and sewage sludge in combination with coal for improvement in energy conversion processes. They concluded the blending impact on tar release, alkali and ash, char characteristics, and thermal co-conversion behaviors. This study will provide recent development and future prospects for cothermal conversion of these blends.
In conclusion, the current special issue offers updated information to the readers on the recent advancements regarding Pollutant Formation and Control during Fuel Thermochemical Conversion and gives a deeper insight into their formation mechanisms and control strategy. It is clearly evidenced that the thermochemical conversion of fossil fuel is a current topic and needs further investigation towards their clean and efficient utilization.

\section{Conflicts of Interest}

The editors declare that they have no conflicts of interest regarding the publication of this special issue.

\section{Acknowledgments}

The editors would like to thank all the authors, reviewers, and the editorial team of the Journal of Chemistry for their great support and contribution in making this special issue possible.

Yanqing Niu
Kuihua Han
Ningbo Gao
Liang Wang
Norbert Miskolczi

\section{References}

[1] A. Williams, J. M. Jones, L. Ma, and M. Pourkashanian, "Pollutants from the combustion of solid biomass fuels," Progress in Energy and Combustion Science, vol. 38, no. 2, pp. 113-137, 2012.

[2] P. Glarborg, J. A. Miller, B. Ruscic, and S. J. Klippenstein, "Modeling nitrogen chemistry in combustion," Progress in Energy and Combustion Science, vol. 67, pp. 31-68, 2018.

[3] Y. Niu, H. Tan, and S. E. Hui, "Ash-related issues during biomass combustion: alkali-induced slagging, silicate meltinduced slagging (ash fusion), agglomeration, corrosion, ash utilization, and related countermeasures," Progress in Energy and Combustion Science, vol. 52, pp. 1-61, 2016.

[4] L. Liu, K. Wang, S. Wang, R. Zhang, and X. Tang, “Assessing energy consumption, $\mathrm{CO}_{2}$ and pollutant emissions and health benefits from China's transport sector through 2050," Energy Policy, vol. 116, pp. 382-396, 2018.

[5] N. Gao, K. Kamran, C. Quan, and P. T. Williams, "Thermochemical conversion of sewage sludge: a critical review," Progress in Energy and Combustion Science, vol. 79, Article ID 100843, 2020. 